\title{
The Effects of a Multivitamin, Multimineral, and Multiantioxidant Supplement on Cardio-Metabolic Risk Biomarkers: A Cross-Sectional Study
}

\author{
Huifeng Jin*, Rolando Lorenzo Maddela, Robert Andrew Sinnott \\ Research and Development, USANA Health Sciences, Inc., Salt Lake City, USA \\ Email address: \\ Huifeng.Jin@usanainc.com (Huifeng Jin),Rolando.Maddela@usanainc.com(R. L. Maddela), Robert.Sinnott@usanainc.com (R. A Sinnott) \\ ${ }^{*}$ Corresponding author
}

\section{To cite this article:}

Huifeng Jin, Rolando Lorenzo Maddela, Robert Andrew Sinnott. The Effects of a Multivitamin, Multimineral, and Multiantioxidant Supplement on Cardio-Metabolic Risk Biomarkers: A Cross-Sectional Study. Journal of Food and Nutrition Sciences.

Vol. 8, No. 5, 2020, pp. 127-138. doi: 10.11648/j.jfns.20200805.12

Received: October 7, 2020; Accepted: October 22, 2020; Published: October 30, 2020

\begin{abstract}
Use of dietary supplements like multivitamins/multiminerals (MVMM) and antioxidant nutrients, is a potentially safe and cost-effective alternative to medications. Dietary supplements-induced health promotion is controversial among available studies, and vast majority studies were done with individual or a subset of dietary supplements. In this study we assessed the effect of a blended supplement (CellSentials), formulated with MVMM and rich phytochemicals antioxidants, on multiple cardio-metabolic risk biomarkers. We recruited 56 subjects (age: $58.8 \pm 1.6$ ) with over one year consumption of blended supplements. Common cardio-metabolic risk biomarkers were measured, including systolic and diastolic blood pressure (SBP and DBP), plasma glucose (Glu), total cholesterol (TC), triglycerides (TGs), high-density cholesterol (HDL-C)), low-density cholesterol (LDL-C), TC: HDL ratio, oxidative stress markers gamma-glutamyltransferase (GGT), and inflammation markers white blood cell (WBC) count, and C-reactive protein (CRP). They were compared to the age, gender and race-matched Non-Users from the National Health and Nutrition Examination Survey (NHANES) 2007-2014 ( $\mathrm{n}=769$, mean age: $55.6 \pm 0.5)$ by multiple linear and logistic regression analyses. Blended supplements users had significantly lower levels of Glucose $(p<0.001)$, TGs $(p<0.001)$, and TC: HDL-C ratio $(p<0.001)$, higher level of HDL-C $(p=0.008)$ as well as lower levels of GGT $(p=0.002)$, CRP $(p=0.007)$ and WBC $(p=0.002)$ than NHANES controls. There were no significant differences in SBP, DBP, TC, LDL-C. Correspondingly, blended supplements users had significantly reduced risks of elevated glucose (OR, 0.21; 95\% CI, $0.07-0.61)$, ratio of TC: HDL-C (OR, 0.08; 95\% CI, $0.02-0.31)$, TGs levels (OR, 0.07; 95\% CI, $0.01-0.4)$, and low HDL-C (OR, $0.23 ; 95 \% \mathrm{CI}, 0.06-0.88)$. These results demonstrated that blended supplement users had healthier pattern in cardio-metabolic biomarkers than control.
\end{abstract}

Keywords: Cardio-Metabolic Risk Biomarkers, Oxidative Stress, Inflammation, MVMMs, Antioxidant Nutrients, NHANES, Multiple Regression

\section{Introduction}

Overweight and obesity epidemics occur widely in the modern world and largely attributed to the unhealthy energyrich but nutrient-poor dietary pattern as well as physical activity shortage. Obesity drastically increases the incidence of metabolic disorders, including diabetes mellitus, dyslipidemia, and hypertension [1]. Reaven first drew attention to the coexistence of metabolic disorders in overweight people [2]. The World Health Organization has declared that around 39\% of world's adults aged 18 years and over were overweight and about $13 \%$ were obese in 2016 [3]. If current trends continue, almost half of the world's adult population will be overweight or obese by 2030 [4]. As a result, the overall prevalence of the triple $\mathrm{H}$ (high blood pressure, hyperglycemia and hyperlipidemias), which are most prevalent modifiable risk factors for cardiovascular disease, is rising worldwide. Effort has been devoted to reducing the risks by lifestyle changes and drug treatment [5, 6]. Despite clinical benefits of lipid-, glucose- and blood 
pressure-lowering medications, there are issues of side effects and intolerance of medications. For example, the incidence of side effects of lipid-lowering medications is estimated to be $5 \%$ to $10 \%$ [7] and about $2 \%$ of patients with dyslipidemia are intolerant of any type of medication [8]. As a potentially safe and cost-effective alternative, dietary supplements use are getting popular and attracting substantial studies [9, 10]. Multivitamins/multiminerals supplements (MVMMs: defined as containing $\geq 3$ vitamins and $\geq 1$ mineral) [11] are the most common type of dietary supplements among adults in the US, followed by the antioxidant nutrients [12], and use is more prevalent among women, older adults, non-Hispanic Whites, and those with higher education and income [13-15]. Additionally, there are growing numbers of supplement products that claim to be beneficial to prevent chronic diseases [16, 17] or for general health and well-being [18]. However, the use of dietary supplements for health promotion is not conclusive [19-24]. Use of dietary supplement have been reported to have impact on cognitive health [25], weight loss [26], obesity [27]. There are also reports that supplementation does not improve cardiovascular outcomes in the general population $[11,28]$.

Numerous previous studies have demonstrated that inflammation and reactive oxygen species (ROS) are two interplay actors [29] that have important roles in the development and progression of cardiovascular disease [30]. Metabolic syndrome (MetS) is associated with a state of lowgrade inflammation, characterized by abnormal proinflammatory cytokine production, increased acute-phase reactants, and activation of a network of inflammatory signaling pathways. MetS has also been linked to oxidative stress, a consequence of a reduction in the antioxidant systems and an increase in the production of reactive oxygen species frequently linked to overconsumption of energy in obesity. Dietary intervention may modulate both proinflammatory state and oxidative stress status related to MetS, thereby decreasing the cardiovascular risk. Numerous dietary nutrients, have anti-inflammatory and antioxidant activity effects, including vitamin $\mathrm{A}, \mathrm{C}, \mathrm{E}$, vitamin B6, $\alpha$ carotene, $\beta$-carotene, $\beta$-cryptoxanthin, lycopene, lutein and zeaxanthin, selenium, magnesium, zinc, copper, iron, fiber, mono- and polyunsaturated fat [31]; as well as other phytochemicals such as curcuminoids [32], green tea [33], coenzyme CoQ10 [34], $\alpha$-lipoic acid [35], resveratrol [36], and quercetin [37]. To date, the vast majority of the studies examine the heath-associations of individual or a subset of nutrients/nutraceuticals. Since nutrients/nutraceuticals likely interact and work synergistically in physiological processes, combined MVMM and bioactive phytochemicals are likely to have synergic and stronger effects on inflammation, oxidative stress and metabolic disorders.

In the present study, we sought to assess the effects of a single formulation, CellSentials (CS), a blended MVMM and phytochemicals-antioxidants product manufactured by USANA Health Sciences, Inc., on the critical cardiometabolic risk factors, oxidative stress markers and inflammation indicators. Our results support a beneficial effect of CellSentials in reducing cardio-metabolic risk factors as well as oxidative stress and inflammation in healthy middle-aged and elderly adults.

\section{Materials and Methods}

\subsection{Study Participants and Data Collection}

Consumers of CS supplement for at least one-year were invited to participate in the survey study. 2256 individuals who resided in the US, Canada or Australia, were invited by electronic mail and 188 agreed to participate in the study. Of those, 179 successfully completed the online lifestyle and health status questionnaire including diet, alcohol use, smoking, exercise, lipid-, glucose-, blood pressuremodifying drug usage and current health status information; 168 successfully completed online demographics including age, gender, race/ethnicity, country of birth, education levels, annual household income and pregnancy status at exam; and dietary supplement usage questionnaire including CellSentials, other USANA supplements as well as nonUSANA supplements usage; 95 successfully uploaded the most recent physical examination document for the records of their weight, height, blood pressure (SBP and DBP), serum nutrients and biomarkers concentrations including fasting blood glucose and lipid profiles (TC, LDL-C, HDL-C and TGs), as well as inflammation markers $\mathrm{C}$-reactive protein (CRP), white blood cell (WBC) counts, and oxidative stress markers GGT (Gamma-glutamyl transferase). Data collection took place between January and August of 2018. A subset of 87 participants had both questionnaire and examination data. Of those, 31 individuals also consumed non-USANA dietary supplements and were excluded. A final number of 56 participants (designated as "CS Users" hereafter) were used for analysis. The study was reviewed and approved by an independent institutional review board of Aspire (IRB: 2018774) (www.aspire-irb.com, CA), and all participants provided informed consent.

\subsection{Non-Users of Supplement from NHANES}

The National Health and Nutrition Examination Survey (NHANES) data was used as the source of comparison data for Non-Users of supplements. NHANES is a stratified, multistage probability sample of the civilian noninstitutionalized U.S. population, conducted by the National Center for Health Statistics. Started in 2007, NHANES includes detailed information about each nutrient amounts in each dietary supplement, allowing accurate estimated of nutrient intakes from dietary supplements in general. To achieve satisfying statistical reliability, we used combined, multiple year (2007-2014) data for this study. The dietary supplement questionnaire (DSQ) was used to collect detailed information on the participant's use of vitamins, minerals, herbals, and other supplements. The analysis was limited to subjects with data available regarding their use of vitamins and nutritional supplements; those with missing data for dietary supplement use were excluded. 
Participants who responded "No" to the question "have you used to take any vitamins, minerals or other dietary supplements in the past month?" were classified as Supplement "Non-Users". Participants who responded "Yes" to the above question were classified as Supplement "Any Users". Since middle-aged persons were more likely to use dietary supplements than young adults [38-40], those younger than 35 years were excluded in this study. In addition, pregnant women were also excluded from this analysis. Further, to match the gender-, age- composition and race- distribution, we selected NHANES 2007-2014 strata with the matched frequency distribution of race/ethnicity ( $>$ $75 \%$ non-Hispanic white) (Figure 1), men and women without pregnancy, and $\geq 35$ years of age, who met supplement non-use criteria.

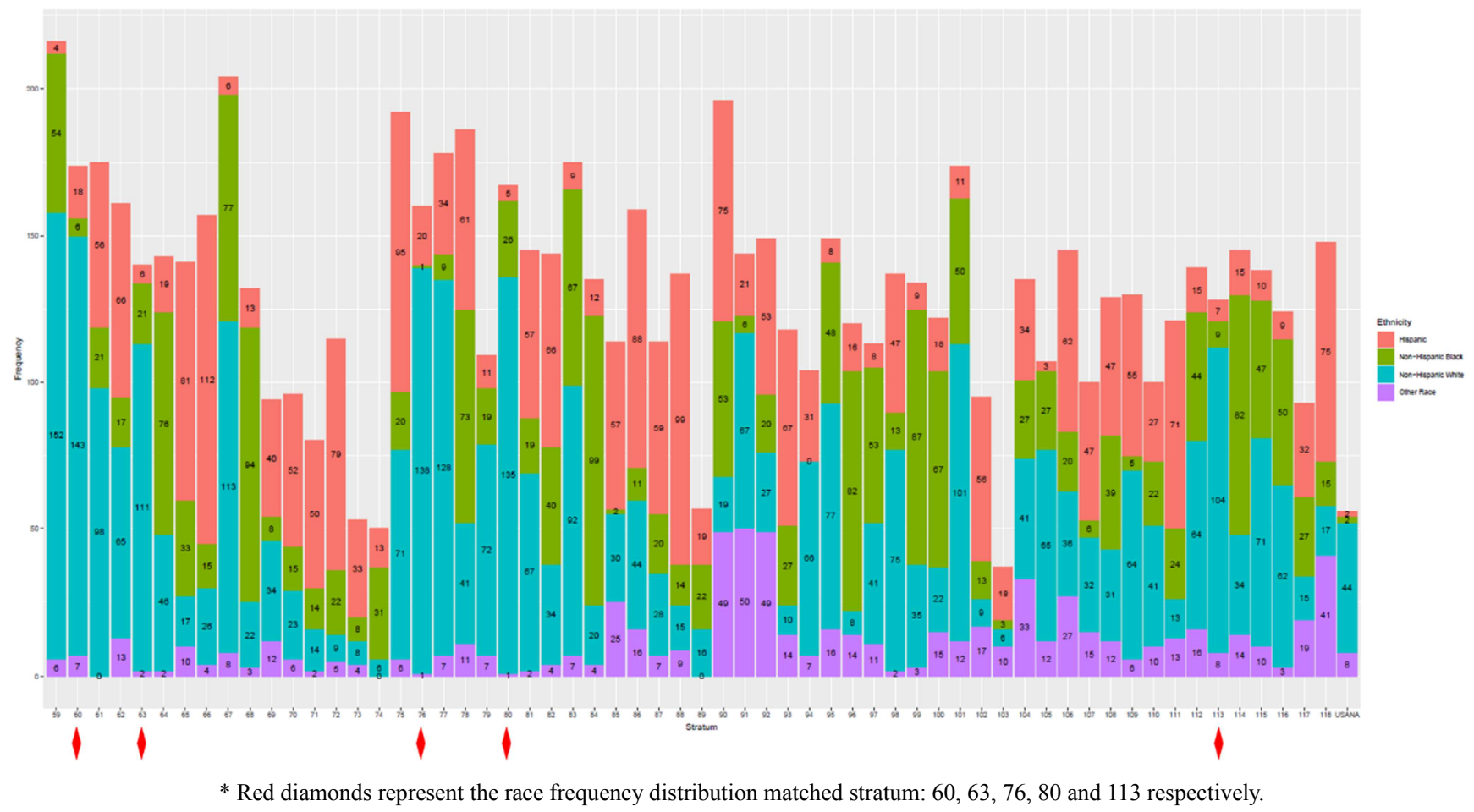

Figure 1. Frequency distribution of race by each stratum in NHANES 2007-2014 data.

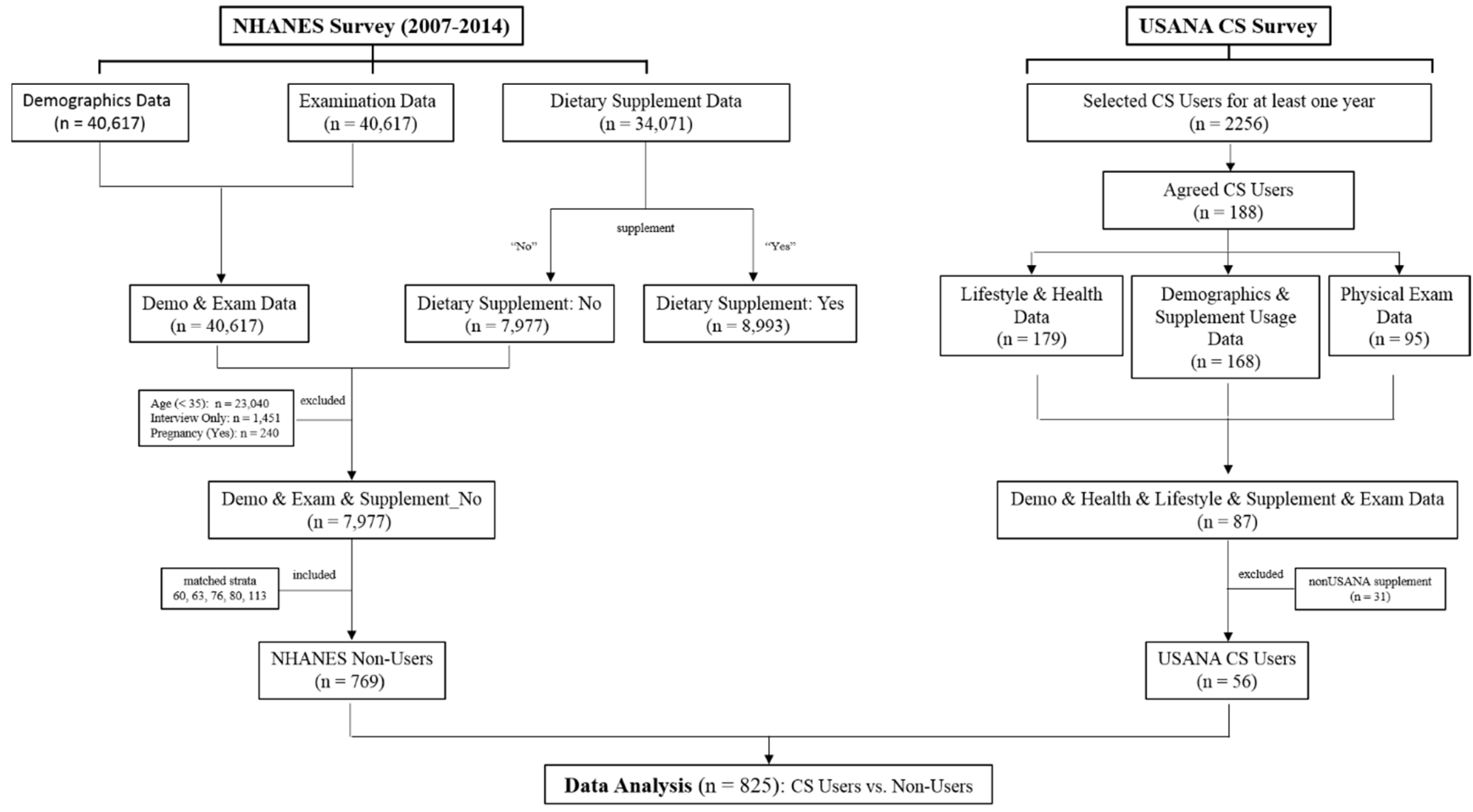

Figure 2. Flow diagram of participants from USANA CellSentials survey and NHANES 2007-2014 survey. 
We identified 769 NHANES participants in five matched strata who did not consume dietary supplements, and served as the "Non-Users" in the analysis. Figure 2 describes the detailed sample identification and selection process.

\subsection{Cardio-metabolic, OS and Inflammation Biomarkers}

The following common cardio-metabolic risk factors as well as oxidative stress (OS) and inflammation biomarkers were studied in the current study: fasting blood glucose (Glu), blood lipid profile including total cholesterol (TC), triglycerides (TGs), high-density cholesterol (HDL-C)), lowdensity cholesterol (LDL-C), systolic/diastolic blood pressure (SBP/DBP); ratio of TC: HDL-C; Gammaglutamyltransferase (GGT), C-reactive protein (CRP), and white blood cell (WBC) count.

\subsection{Definition of the Cardio-metabolic Risk Factors}

As commonly used in clinics, elevated blood pressure was defined as $>=85 \mathrm{mmHg}$ for diastolic and/or $>=130 \mathrm{mmHg}$ for systolic blood pressure or taking antihypertensive medications [41]. Elevated biomarker concentrations were defined as: $>=100 \mathrm{mg} / \mathrm{dL}$ for fasting plasma glucose or any use of insulin or glucose-lowering drugs; $>=200 \mathrm{mg} / \mathrm{dL}$ for TC or taking lipid lowering medications; $>=130 \mathrm{mg} / \mathrm{dL}$ for LDL-cholesterol or taking lipid lowering medications; $>=150$ $\mathrm{mg} / \mathrm{dL}$ for TG or taking lipid lowering medications; $<40$ $\mathrm{mg} / \mathrm{dL}$ for HDL-cholesterol for men and $<50 \mathrm{mg} / \mathrm{dL}$ for women or taking lipid lowering medications; $>=5$ for the ratio of TC to HDL-cholesterol, an indicator of dyslipidemia and correlate well with risk of cardiovascular disease [42].

\subsection{Statistical Analyses}

Data were analyzed using R 3.4.1. We conducted the analyses according to the guidelines recommended by the Centers for Disease Control for analysis of complex NHANES data set accounting for the masked variance and using the proposed weighting methodology [43]. Analyses included descriptive analyses, Pearson correlation tests, multiple linear and logistic regression. The unadjusted differences in means between user groups were tested using a two-sided independent sample $t$ tests. Associations between categorical variables were tested using chi-square tests. Moreover, adjusted differences in means and odds ratios were estimated using multiple linear and logistic regression models, respectively. All $\mathrm{P}$ values were 2 -sided; $\mathrm{P}<0.05$ was considered statistically significant after Benjamini-Hochberg correction for false discovery rate because of the number of hypotheses being tested.

After combining the USANA CS Users with matched NonUsers from NHANES, data were reweighted. The weights were calculated by combining the 8 -year weights using the correct proportion of each, then the weights of the matched 5 strata of Non-Users were calculated by dividing each NHANES Non-User weight by the sum of the NHANES weights of that Non-Users group. Appropriate weights were used from the Mobile Examination Center. The CS Users were assigned a weight of 1 . Strata and primary sampling units from NHANES were used for Non-Users group. For the CS Users, a new stratum variable was assigned, and each member of the USANA CS Users group was assigned to a unique primary sampling unit. These adjustments permit more accurate variance estimates and account for stratification factors. Because of skewed distributions of systolic blood pressure, fasting glucose, TC, HDL-C, TGs levels, as well as OS markers (GGT) and inflammation markers (CRP, WBC), ln-transformed values were used to improve normality and geometric means were presented when they were dependent variables. Multiple linear and logistic regression model was employed to examine the systolic/diastolic blood pressure and cardio-metabolic biomarkers concentrations adjusted for age, gender and ethnicity. Considering possible limited sample size for OS and inflammation markers, each potential confounding factor (age, gender and ethnicity) was examined separately in the models. Factors statistically significant at $a=0.05$ were evaluated in multivariable analysis with forward stepwise selection and covariates significant at $\mathrm{a}=0.05$ were retained. Then correlations between significant markers of OS and inflammation were determined using Pearson's correlation.

\section{Results}

Ingredient of Cellsentials dietary supplement include multivitamins (vitamin A, C, E, D3, K, B1, B2, B3, B5, B6, B7, B9, B12), antioxidant nutrients (CoQ10, lutein, lycopene, Incelligence Complex with alpha lipoic acid, curcumin, green tea extract, quercetin dihydrate, rutin hesperidin and resveratrol), and core minerals (calcium, iodine, magnesium, zinc, selenium, copper, manganese, chromium, molybdenum, boron, silicon, vanadium, ultra-trace minerals and $\mathrm{N}$-acetyl L-cycteine) (Table 1).

Table 1. CellSentials Supplement facts list.

\begin{tabular}{|c|c|c|}
\hline \multicolumn{3}{|l|}{ US Vita Antioxidant } \\
\hline \multicolumn{3}{|c|}{$\begin{array}{l}\text { Other ingredients: Microcrystalline Cellulose, Modified Starch, Croscarmellose Sodium, Silicon Dioxide, Ascorbyl Palmitate, Organic } \\
\text { Maltodextrin, Vanilla Extract, Organic Sunflower, Lecithin, Organic Palm Olein, Organic Guar Gum. }\end{array}$} \\
\hline \multicolumn{3}{|l|}{ Supplement Facts } \\
\hline \multicolumn{3}{|l|}{ Serving size: 2 tablets } \\
\hline Amount per serving & & $\% \mathrm{DV}$ \\
\hline Vitamin A (as $25 \%$ retinyl acetate, and $75 \%$ [ $4500 \mathrm{IU}]$ as beta carotene and mixed carotenoids) & $6000 \mathrm{IU}$ & $120 \%$ \\
\hline Vitamin $\mathrm{C}$ (as poly $\mathrm{C}$ blend: potassium, calcium, magnesium and zinc ascorbates) & $200 \mathrm{mg}$ & $330 \%$ \\
\hline Vitamin D3 (as cholecalciferol) & $1000 \mathrm{IU}$ & $250 \%$ \\
\hline Vitamin E (as D-alpha tocopheryl succinate) & $100 \mathrm{IU}$ & $330 \%$ \\
\hline
\end{tabular}




\begin{tabular}{|c|c|c|}
\hline \multirow{2}{*}{\multicolumn{3}{|c|}{$\begin{array}{l}\text { US Vita Antioxidant } \\
\text { Other ingredients: Microcrystalline Cellulose, Modified Starch, Croscarmellose Sodium, Silicon Dioxide, Ascorbyl Palmitate, Organic } \\
\text { Maltodextrin, Vanilla Extract, Organic Sunflower, Lecithin, Organic Palm Olein, Organic Guar Gum. }\end{array}$}} \\
\hline & & \\
\hline \multicolumn{3}{|c|}{ Supplement Facts } \\
\hline \multicolumn{3}{|l|}{ Serving size: 2 tablets } \\
\hline Amount per serving & & $\% \mathrm{DV}$ \\
\hline Vitamin K (as K1 [phytonadione] and k2 [mk-7 menaquinone]) & 270 ug & $340 \%$ \\
\hline Vitamin B1 (as thiamin HCL) & $15 \mathrm{mg}$ & $1000 \%$ \\
\hline Vitamin B2 (as riboflavin) & $15 \mathrm{mg}$ & $880 \%$ \\
\hline Niacin (as niacinamide and niacin) & $20 \mathrm{mg}$ & $100 \%$ \\
\hline Vitamin B6 (as pyridoxine $\mathrm{HCL}$ ) & $16 \mathrm{mg}$ & $800 \%$ \\
\hline Folate (as folic acid) & $300 \mathrm{ug}$ & $80 \%$ \\
\hline Vitamin B12 (as cyanocoalamin) & $100 \mathrm{ug}$ & $1670 \%$ \\
\hline Biotin & 150 ug & $50 \%$ \\
\hline Pantothenic aci (as D-calcium pantothenate) & $45 \mathrm{mg}$ & $450 \%$ \\
\hline Mixed tocopherols (D-gamma, D-delta, D-beta tocopherol) & $40 \mathrm{mg}$ & $\dagger$ \\
\hline \multicolumn{3}{|l|}{ Incelligence $\mathrm{TM}^{\mathrm{TM}}$ complex } \\
\hline Alpha lipoic acid & $50 \mathrm{mg}$ & \\
\hline Meriva bioavailable curcumin complex [curcuma longa 1., root] & $36 \mathrm{mg}$ & \\
\hline Green tea extract [camellia sinensis hunt., leaves] & $35 \mathrm{mg}$ & \\
\hline Quercetin dihydrate & $30 \mathrm{mg}$ & \\
\hline Rutin & $20 \mathrm{mg}$ & \\
\hline Hesperidin [citrus spp. L., fruit] & $20 \mathrm{mg}$ & \\
\hline Resveratrol & $20 \mathrm{mg}$ & \\
\hline Olivol [olive fruit extract, olea europaea 1., fruit] & $15 \mathrm{mg}$ & \\
\hline Inositol & $64 \mathrm{mg}$ & $\dagger$ \\
\hline Choline bitartrate & $125 \mathrm{mg}$ & $\dagger$ \\
\hline Coenzyme Q10 & $6 \mathrm{mg}$ & $\dagger$ \\
\hline Lutein (tagetes erecta 1., flower) & $300 \mathrm{ug}$ & $\dagger$ \\
\hline Lycopene & $500 \mathrm{ug}$ & $\dagger$ \\
\hline
\end{tabular}

\begin{tabular}{|c|c|c|}
\hline \multicolumn{3}{|l|}{ US Core Minerals } \\
\hline \multicolumn{3}{|c|}{$\begin{array}{l}\text { Other ingredients: Microcrystalline Cellulose, Modified Starch, Croscarmellose Sodium, Ascorbyl Palmitate, Organic Maltodextrin, } \\
\text { Pregelatinized Starch, Silicon Dioxide, Vanilla Extract, Organic Sunflower, Lecithin, Organic Palm Olein, Organic Guar Gum. }\end{array}$} \\
\hline \multicolumn{3}{|c|}{ Supplement Facts } \\
\hline \multicolumn{3}{|l|}{ Serving size: 2 tablets } \\
\hline Amount Per Serving & & \%DV \\
\hline Vitamin C (as magnesium ascorbate and calcium ascorbate) & $300 \mathrm{mg}$ & $500 \%$ \\
\hline Calcium (as calcium citrate and calcium ascorbate) & $112.5 \mathrm{mg}$ & $10 \%$ \\
\hline Iodine (as potassium iodide) & $250 \mathrm{ug}$ & $170 \%$ \\
\hline Magnesium (as magnesium citrate and magnesium ascorbate) & $112.5 \mathrm{mg}$ & $30 \%$ \\
\hline Zinc (as zinc citrate) & $10 \mathrm{mg}$ & $70 \%$ \\
\hline Selenium (as L-selenomethionine and sodium selenite) & $100 \mathrm{ug}$ & $140 \%$ \\
\hline Copper (as copper gluconate) & $1 \mathrm{mg}$ & $50 \%$ \\
\hline Manganese (as manganese gluconate) & $1 \mathrm{mg}$ & $50 \%$ \\
\hline Chromium (as chromium polynicotinate) & $150 \mathrm{ug}$ & $130 \%$ \\
\hline Molybdenum (as molybdenum citrate) & $25 \mathrm{ug}$ & $35 \%$ \\
\hline Boron (as boron citrate) & $1500 \mathrm{ug}$ & $\dagger$ \\
\hline Silicon (as calcium silicate) & $2 \mathrm{mg}$ & $\dagger$ \\
\hline Vanadium (as vanadium citrate) & $20 \mathrm{ug}$ & $\dagger$ \\
\hline Ultra trace minerals & $1500 \mathrm{ug}$ & $\dagger$ \\
\hline $\mathrm{N}$-acetyl L-cysteine & $80 \mathrm{mg}$ & $\dagger$ \\
\hline
\end{tabular}

$\dagger$ Daily Values not established.

Significant differences by user groups were found for gender, ethnicity and self-reported health status with more older-aged white females taking CS supplement. $(\mathrm{p}<0.001)$ (Table 2). The CS users are marginally statistically older than Non-users $(\mathrm{p}=0.055)$. Also 91\% USANA CS Users reported that they are healthy $(p<0.001)$. As shown in Table 2, mean biomarker values for CS users were significantly lower in SBP (119.1 vs. $127.4 \mathrm{~mm} \mathrm{Hg} \mathrm{(-6.5 \% )),} \mathrm{glucose} \mathrm{(98.6} \mathrm{vs.}$
$113.9 \mathrm{mg} / \mathrm{dL}(-13.4 \%))$, TGs (122.4 vs. $161.5 \mathrm{mg} / \mathrm{dL}(-$ $24.2 \%)$ ), TC: HDL-C ratio (3.8 vs. $4.5(-15.6 \%))$ and higher in HDL-C (60.5 vs. $49.4 \mathrm{mg} / \mathrm{dL}(22.5 \%)$ compared to NHANES Non-Users. In addition, CS Users are higher in TC (212.5 vs. $200.3 \mathrm{mg} / \mathrm{dL}(6.1 \%))$ than NHANES Non-users. There were no significant differences in DBP (72.9 vs. 72.2 $(\mathrm{mm} \mathrm{Hg})(1 \%))$ and LDL-C (127.2 vs. $117.9 \mathrm{mg} / \mathrm{dL}(7.9 \%))$. 
Table 2. Participant characteristics by dietary supplement use.

\begin{tabular}{|c|c|c|c|c|}
\hline & Overall & USANA CS Users & NHANES Non-Users & p Value \\
\hline Participants & 825 & 56 & 769 & \\
\hline Age $($ mean $\pm \mathrm{SE})$ & $55.82 \pm 0.48$ & $58.83 \pm 1.58$ & $55.6 \pm 0.5$ & 0.055 \\
\hline Gender ( $\%$ Female $)$ & 0.47 & 0.73 & 0.45 & $<0.001$ \\
\hline Ethnicity (\%) & & & & $<0.001$ \\
\hline Hispanic & 0.07 & 0.04 & 0.07 & \\
\hline Non-Hispanic Black & 0.08 & 0.04 & 0.08 & \\
\hline Non-Hispanic White & 0.82 & 0.79 & 0.82 & \\
\hline Other Race & 0.03 & 0.14 & 0.02 & \\
\hline Health Status (\%) & & & & $<0.001$ \\
\hline Excellent or Very Good & 0.36 & 0.91 & 0.32 & \\
\hline Non-Fair or Poor & 0.22 & 0.04 & 0.23 & \\
\hline Good & 0.34 & 0.05 & 0.36 & \\
\hline Don't Know & 0.08 & 0.00 & 0.09 & \\
\hline Systolic blood pressure $(\mathrm{mmHg})($ mean $\pm \mathrm{SE})$ & $127.17 \pm 0.71(n=736)$ & $119.12 \pm 2.96(n=24)$ & $127.44 \pm 0.73(n=712)$ & 0.011 \\
\hline Diastolic Blood Pressure $(\mathrm{mm} \mathrm{Hg})($ mean $\pm \mathrm{SE})$ & $72.26 \pm 0.47(n=736)$ & $72.92 \pm 1.9(n=24)$ & $72.24 \pm 0.48(\mathrm{n}=712)$ & 0.731 \\
\hline Total Cholesterol $(\mathrm{mg} / \mathrm{dL})($ mean $\pm \mathrm{SE})$ & $200.88 \pm 1.57(\mathrm{n}=764)$ & $212.46 \pm 5.31(n=39)$ & $200.26 \pm 1.62(\mathrm{n}=725)$ & 0.033 \\
\hline LDL Cholesterol $(\mathrm{mg} / \mathrm{dL})($ mean $\pm \mathrm{SE})$ & $118.7 \pm 1.82(\mathrm{n}=384)$ & $127.16 \pm 4.43(n=35)$ & $117.85 \pm 1.95(\mathrm{n}=349)$ & 0.060 \\
\hline HDL Cholesterol $(\mathrm{mg} / \mathrm{dL})($ mean $\pm \mathrm{SE})$ & $49.86 \pm 0.59(\mathrm{n}=760)$ & $60.48 \pm 3.18(n=35)$ & $49.35 \pm 0.59(\mathrm{n}=725)$ & 0.001 \\
\hline Triglycerides $(\mathrm{mg} / \mathrm{dL})($ mean $\pm \mathrm{SE})$ & $157.87 \pm 6.19(n=399)$ & $122.39 \pm 11.84(\mathrm{n}=37)$ & $161.5 \pm 6.69(n=362)$ & 0.006 \\
\hline Ratio of TC: HDL $($ mean \pm SE) & $4.42 \pm 0.07(\mathrm{n}=760)$ & $3.75 \pm 0.19(n=35)$ & $4.45 \pm 0.07(\mathrm{n}=725)$ & $<0.001$ \\
\hline
\end{tabular}

Next, adjusted mean differences of blood pressure and each biomarkers as well as their risk estimates (odds ratios) were calculated using multiple linear and logistic regression. The CS users showed significant decrease in geometric mean concentrations of fasting blood glucose $(p<0.001)$, TGs $(p<$ $0.001)$ and mean of ratio of TC: HDL $(p<0.001)$, and significant increase in geometric mean concentration of HDL-C $(p=0.008)$ compared to Non-users. However, there was no significant difference between two groups in levels of SBP, DBP and TC after Benjamini-Hochberg adjusted comparisons (Figure 3).

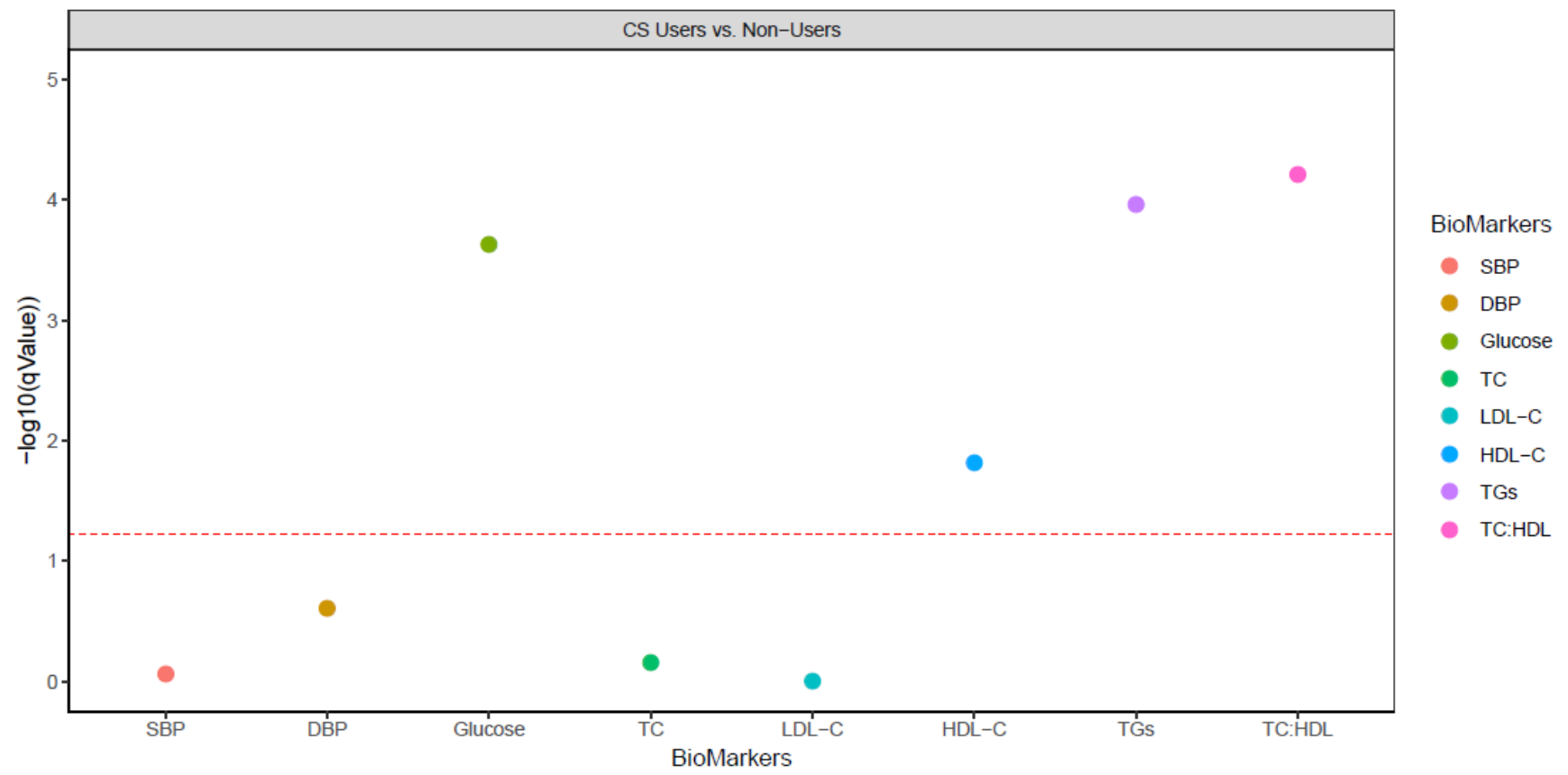

Figure 3. Adjusted multiple linear regression methods to assess the associations of each cardio-metabolic risk factor with CellSentials use. The $x$ axis represents cardio-metabolic risk factors; qValue represents p value after Benjamini-Hochberg adjusted comparisons, y axis represents -log10 ( $q$ Value) of each cardio-metabolic risk factor analysis. Red dashed line represents the cutoff statistical significance after Benjamini-Hochberg False Discovery Threshold at $P=0.05$ comparison. Dots above the red dashed line represent statistically significance.

Adjusted risk estimates for elevated blood pressure and elevated concentrations of serum biomarkers are reported in Table 3. Correspondingly, CS Users had significantly reduced risks of elevated blood glucose (OR, 0.21; 95\% CI, 0.07 -
0.61), ratio of TC: HDL-C (OR, 0.08; 95\% CI, $0.02-0.31)$, TGs levels (OR, 0.07; 95\% CI, $0.01-0.4)$, and significantly reduced risk of low HDL-C (OR, 0.23; 95\%CI, $0.06-0.88$ ). Risks of elevated BP, TC and LDL-C did not significantly 
differ from Non-Users.

Table 3. Risk of elevated cardio-metabolic factor levels by supplement user group.

\begin{tabular}{|c|c|c|c|}
\hline Outcome & Cases: n (\%) & OR & $95 \%$ CI \\
\hline \multicolumn{4}{|c|}{ Elevated blood pressure (systolic $\geq 130 \mathrm{~mm} \mathrm{Hg}$, or diastolic $\geq 85 \mathrm{mmHg}$ ) } \\
\hline CS Users & $6 /(25)$ & 0.42 & $(0.05-3.22)$ \\
\hline Non-Users & $424 /(59.6)$ & 1.00 & \\
\hline \multicolumn{4}{|c|}{ Elevated fasting glucose $(\geq 100 \mathrm{mg} / \mathrm{dL})$} \\
\hline CS Users & $9 /(25)$ & 0.21 & $(0.07-0.61) * *$ \\
\hline Non-Users & $235 /(64.4)$ & 1.00 & \\
\hline \multicolumn{4}{|c|}{ Total cholesterol (>200 mg/dL) } \\
\hline CS Users & $26 /(66.7)$ & 0.39 & $(0.11-1.34)$ \\
\hline Non-Users & $438 /(60.4)$ & 1.00 & \\
\hline \multicolumn{4}{|c|}{ LDL-cholesterol (>130 mg/dL) } \\
\hline CS Users & 17/(48.6) & 0.48 & $(0.18-1.3)$ \\
\hline Non-Users & $179 /(51.3)$ & 1.00 & \\
\hline \multicolumn{4}{|c|}{ HDL-cholesterol ( $<40 \mathrm{mg} / \mathrm{dL}$ for males, $<50 \mathrm{mg} / \mathrm{dL}$ for females) } \\
\hline CS Users & $8 /(22.9)$ & 0.23 & $(0.06-0.88) *$ \\
\hline Non-Users & $376 /(51.9)$ & 1.00 & \\
\hline \multicolumn{4}{|c|}{ Triglycerides $(\geq 150 \mathrm{mg} / \mathrm{dL})$} \\
\hline CS Users & $12 /(32.4)$ & 0.07 & $(0.01-0.4) * *$ \\
\hline Non-Users & $184 /(50.8)$ & 1.00 & \\
\hline \multicolumn{4}{|c|}{ Ratio of total cholesterol to HDL-cholesterol $(\geq 5)$} \\
\hline CS Users & $7 /(20)$ & 0.08 & $(0.02-0.31) * * *$ \\
\hline Non-Users & $324 /(44.7)$ & 1.00 & \\
\hline
\end{tabular}

Adjusted odds ratios with $95 \%$ confidence interval of each cardio-metabolic risk factor by CS Users with Non-Users as a reference using multiple logistic regression analysis.

$* \mathrm{P}<0.05 ; * * \mathrm{P}<0.01 ; * * * \mathrm{P}<0.001$.

$\mathrm{CI}$, confidence interval; OR, odds ratio.

Lastly, we investigated relationships between CS supplementation and markers of OS and inflammation. After adjusting for relevant covariates, CS supplementation was associated with a decrease in CRP, GGT and WBC. The most striking inverse association was observed for the oxidative stress marker GGT, where CS supplementation was associated with a $47.7 \%$ decrease in blood GGT concentration $(16.111 \pm 1.273$ vs. $30.799 \pm 0.859 \mathrm{U} / \mathrm{L}$, $\mathrm{p}=0.002$ ). Additionally, CS supplementation was associated with a $25.2 \%$ and a $19.2 \%$ decrease in total WBC count
$(5.694 \pm 0.29$ vs. $7.617 \pm 0.11 \mathrm{~K} / \mathrm{uL}, \mathrm{p}=0.002)$ and serum concentrations of CRP $(0.366 \pm 0.21$ vs. $0.453 \pm 0.03 \mathrm{mg} / \mathrm{dL}$, $\mathrm{p}=0.007$ ) respectively. (Figure 4). Next we calculated the Pearson correlation coefficients between significant OS marker GGT and significant inflammation markers CRP and WBC to test the correlations between OS and inflammation. GGT levels show a both positive correlation with increasing markers of inflammation CRP levels $(r=0.31, p<0.001)$ and WBC count (as a general parameter of the immune system state) $(r=0.2, p<0.001)$.
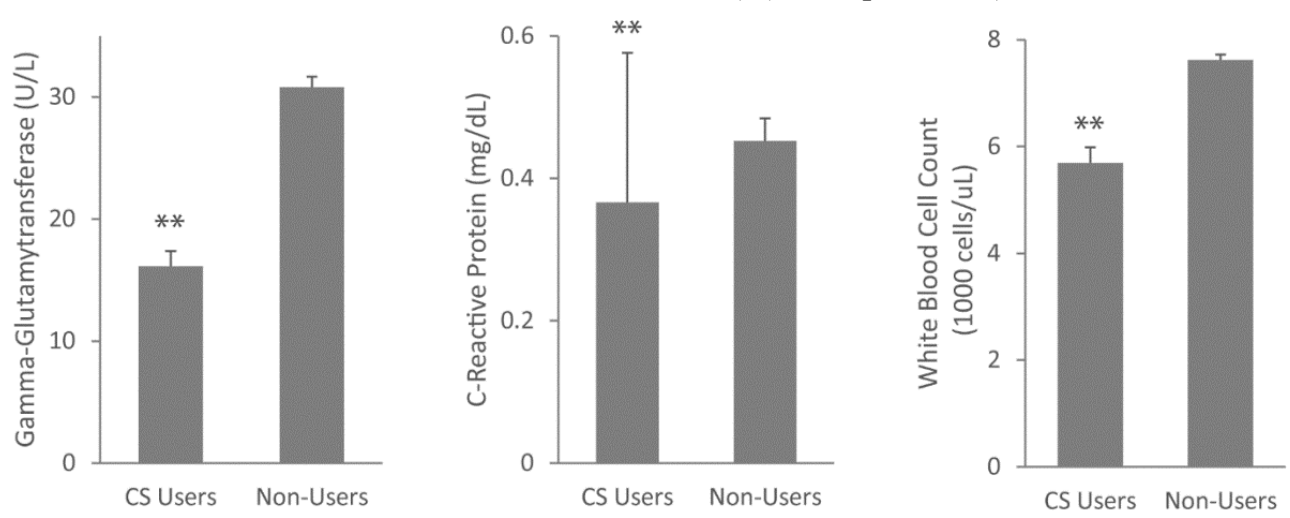

Figure 4. Serum levels of gamma-glutamyl transferase (GGT), C-reactive protein (CRP) and white blood cell (WBC) count between CS supplement use and NHANES "Non-Users". **P $<0.01$.

\section{Discussion}

Overall, the results showed that CS supplement users were more likely to be older, female, White, which was consistent with the reports of US populations examined in the
NHANES $[14,15]$. Importantly, we found that individuals who use dietary supplements are healthier in the present study (Table 2). The CS users were observed to have significantly lower levels in glucose, TGs and ratio of TC: HDL-C as well as higher levels in HDL-C, with lower risk of elevated glucose, TGs, ratio of TC: HDL-C and reduced 
HDL-C levels adjusted for age, gender and race. In addition, OS markers GGT values and inflammation markers CRP and WBC were observed to be lower in CS users.

The use of alternative therapies like herbs and dietary supplements is very common among hypertensive, diabetic (hyperglycaemic) and hyperlipidemic patients all over the globe [44]. In vitro and in vivo studies have shown that vitamins/minerals and phytochemicals have important roles in improving insulin sensitivity, insulin production/action, as well as carbohydrate, lipid and protein metabolisms, which collectively lead to the control of the excessive oxidative stress and pancreatic beta-cell dysfunction [31, 45, 46]. Vitamins, minerals and phytochemicals also promote the enhancement of endothelial function and the reduced production of growth factors such as angiotensin and endothelins, all of which are associated with the control of hypertension, hyperglycemia and hyperlipidemia [47-52].

We found that CS supplement use was associated with lower TGs and higher HDL-C concentrations with significantly lower risk of an elevated ratio of TC: HDL-C in supplement users (Tables 2 and 3, Figure 3). These results support common practice of using fish oil, vitamin E [53], vitamin D [54], vitamin B6 and B12 [55], folate [56], niacin [57], magnesium [58], zinc [59], chromium and biotin [60, 61], calcium and iron [62], selenium [63] and CoQ10 [64], in the dietary intervention of blood lipid profile.

Dietary MVMM have been shown to reduce blood pressure [65]. Dietary folate and vitamin C, as well as plasma ascorbic acid, have been found to be inversely associated with blood pressure in observational studies [66, 67]. Multiple nutrition components have been reported to be effective at lowering blood pressure including vitamin $\mathrm{C}$ [68], -D [54], -E [69], -B6 [70], -B12, folate [71, 72], niacin [73], thiamine [74], riboflavin [75], magnesium [58], iron [76], calcium [77] and CoQ10 [78]. Consistently, in the present study, significant reduction of SBP was observed in unadjusted analysis $(119.12 \pm 2.96$ vs. $127.44 \pm 0.73 \mathrm{mmHg}$, $\mathrm{p}=0.011$ ) (Table 2). However, no significant reduction in risk of elevated BP was observed after controlling for age, gender and race (OR, 0.42; 95\% CI, $0.05-3.22$ ) (Table 3$)$. It is possible that the non-significant result is due to the small sample size (only 24 participants have SBP/DBP values in the CS user group in the present study) and the resulting large variation.

The study showed significant lower levels of glucose as well as correspondingly lower risk of elevated glucose level in USANA CS users (Tables 2 and 3, Figure 3). This is consistent with previous studies that showing folate [79], vitamin E [80], -C [81], -B6 [82], -B12 [83], niacin [84], thiamine [85], magnesium [58], chromium [60], zinc [86] and copper $[87,88]$ have some beneficial effects on insulin action, glycaemic control and endothelial function. Notably, a meta-analysis of 18 trials with 21,081 subjects reported that folate supplementation significantly decreased glucose level [79].

CS supplement is rich in antioxidant nutrients including vitamins $\mathrm{C}$ and $\mathrm{E}, \mathrm{CoQ} 10$, lutein, lycopene, alpha lipoic acid, curcumin, green tea extract, quercetin dihydrate, rutin hesperidin and resveratrol. Cardiometabolic diseases are closely-associated with oxidative stress and inflammation. As expected, we were able to show that CS supplementation significantly reduced serum GGT, the oxidative stress biomarker, and CRP level and WBC counts, two inflammation markers (Figure 4) GGT is a transferase that catalyzes the transfer of gamma-glutamyl functional groups. It plays a key role in the synthesis and degradation of glutathione (GSH), which is the most abundant thiol in animal cells and is critical in preventing damage to cellular components caused by reactive oxygen species (ROS) such as free radicals and peroxides. Evidences from previous studies suggests that GGT levels correlate positively with cardiovascular risk factors such as CRP and inversely with antioxidant levels $[89,90]$. The function of serum CRP (Creactive protein) is to bind to the lysophosphatidylcholine on the surface of dying/degenerating cells, activating the complement system to promote phagocytosis by macrophages. Recent researches have established that elevated basal levels of CRP are associated with various risks of cardiometabolic diseases.

Our study did not address the mechanisms of how antioxidant nutrients may decrease oxidative stress and inflammation, but numerous previous studies have established that there are multiple ways. Antioxidants, including lipoic acid, carotenoids, lutein, lycopene, vitamin $\mathrm{C}$, vitamin $\mathrm{E}$, and flavonoids, can directly bind to ROS and terminate free radical chain reactions, thus protect DNA, protein, and lipids from ROS attacks and subsequent oxidative stress. Antioxidant nutrients and their metabolites, may also be capable of regulating antioxidant enzymes activities therefore balance of oxidation-reduction reaction. For example, curcumin can induce and increase antioxidant enzymes activities including glutathione peroxidase and glutathione S-transferase. Further, antioxidant nutrients can regulate pro-inflammation cell signaling pathways. An important target is nuclear factor kappa B (NF-kB) and IkB kinase and downstream inflammatory cytokine/chemokine signaling pathways that can be inhibited by curcumin, CoQ10, and catechins [32, 34, 91].

The study has limitations. The datasets relied on selfreported measures of dietary supplement use, which is subject to recall bias, and over or under reporting. Second, although the present study adjusted for some potential confounding variables, residual confounding or confounding from unknown or unmeasured factors cannot be completely excluded. The results could be confounded by unmeasured biological and genetic factors. Third, due to the most recent physical examination document was used for biomarkers in the present study, the examination time and location/center varied, therefore, there are fewer samples available for analysis for these biomarker outcome measures, in addition, there was no access to other commonly used serum antioxidants such as vitamin $\mathrm{C}$ and $\mathrm{E}$. Studies with greater sample sizes may prove more informative. Fourth, this is a cross-sectional observation, therefore the reported 
associations, cannot presume causality. Further studies are needed to confirm the effectiveness of the product, as well as understand the biological mechanisms underlying the observed associations.

\section{Conclusion}

The findings from the present study demonstrate that blended dietary multivitamins/multiminerals and antioxidants nutrients supplement improve cardio-metabolic biomarker levels and is associated with lower risk of hyperglycemia and hyperlipidemia. Further studies using well-designed longitudinal cohort studies and randomized placebocontrolled trials, are warranted to provide stronger evidence and establish causal inference.

\section{Abbreviations}

MVMM (multivitamins/multiminerals), CS (CellSentials), systolic and diastolic (SBP and DBP), glucose (Glu), total cholesterol (TC), triglycerides (TGs), high-density cholesterol (HDL-C), low-density cholesterol (LDL-C), gamma-glutamyl transferase (GGT), C-reactive protein (CRP), white blood cells (WBC), OS (Oxidative Stress), National Health and Nutrition Examination Survey (NHANES)

\section{Author Contributions}

H. J., R. L. M. and R. A. S. conceived and designed the study. H. J. analyzed the data. H. J. wrote the manuscript. H. J. and R. L. M. edited the manuscript. All authors have read and approved the final manuscript.

\section{Funding}

This research is funded by USANA Health Sciences, Inc.

\section{Conflicts of Interest}

H. J., R. L. M. and R. A. S. are employed by USANA Health Sciences, Inc. The authors declare that they have no competing interests.

\section{Acknowledgements}

We thank Marie Mullen for her assistance in performing the survey.

\section{References}

[1] Zimmet, P.; Alberti, K. G.; Shaw, J. Global and societal implications of the diabetes epidemic. Nature 2001, 414, 782787, doi: $10.1038 / 414782 a$.

[2] Reaven, G. M.; Chen, Y. D. Role of insulin in regulation of lipoprotein metabolism in diabetes. Diabetes Metab Rev 1988, 4, 639-652.
[3] WHO: https://www.who.int/en/news-room/factsheets/detail/obesity-and-overweight.

[4] Kelly, T.; Yang, W.; Chen, C. S.; Reynolds, K.; He, J. Global burden of obesity in 2005 and projections to 2030. Int J Obes (Lond) 2008, 32, 1431-1437, doi: 10.1038/ijo.2008.102.

[5] Chobanian, A. V.; Bakris, G. L.; Black, H. R.; Cushman, W. C.; Green, L. A.; Izzo, J. L., Jr.; Jones, D. W.; Materson, B. J.; Oparil, S.; Wright, J. T., Jr., et al. Seventh report of the Joint National Committee on Prevention, Detection, Evaluation, and Treatment of High Blood Pressure. Hypertension 2003, 42, 1206-1252, doi: 10.1161/01.HYP.0000107251.49515.c2.

[6] Expert Panel on Detection, E.; Treatment of High Blood Cholesterol in, A. Executive Summary of The Third Report of The National Cholesterol Education Program (NCEP) Expert Panel on Detection, Evaluation, And Treatment of High Blood Cholesterol In Adults (Adult Treatment Panel III). JAMA 2001, 285, 2486-2497, doi: 10.1001/jama.285.19.2486.

[7] Thompson, P. D.; Clarkson, P.; Karas, R. H. Statin-associated myopathy. JAMA 2003, 289, 1681-1690, doi: 10.1001/jama.289.13.1681.

[8] Becker, D. J.; Gordon, R. Y.; Morris, P. B.; Yorko, J.; Gordon, Y. J.; Li, M.; Iqbal, N. Simvastatin vs therapeutic lifestyle changes and supplements: randomized primary prevention trial. Mayo Clin Proc 2008, 83, 758-764, doi: 10.4065/83.7.758.

[9] Bronzato, S.; Durante, A. Dietary Supplements and Cardiovascular Diseases. International journal of preventive medicine 2018, 9, 80, doi: 10.4103/ijpvm.IJPVM_179_17.

[10] Hill, A. M.; Fleming, J. A.; Kris-Etherton, P. M. The role of diet and nutritional supplements in preventing and treating cardiovascular disease. Current opinion in cardiology 2009, 24, 433-441, doi: 10.1097/HCO.0b013e32832f2fb1.

[11] Kim, J.; Choi, J.; Kwon, S. Y.; McEvoy, J. W.; Blaha, M. J.; Blumenthal, R. S.; Guallar, E.; Zhao, D.; Michos, E. D. Association of Multivitamin and Mineral Supplementation and Risk of Cardiovascular Disease: A Systematic Review and Meta-Analysis. Circ Cardiovasc Qual Outcomes 2018, 11, e004224, doi: 10.1161/CIRCOUTCOMES.117.004224.

[12] Thompson, H. J.; Heimendinger, J.; Diker, A.; O'Neill, C.; Haegele, A.; Meinecke, B.; Wolfe, P.; Sedlacek, S.; Zhu, Z.; Jiang, W. Dietary botanical diversity affects the reduction of oxidative biomarkers in women due to high vegetable and fruit intake. $J$ Nutr 2006, 136, 2207-2212, doi: 10.1093/jn/136.8.2207.

[13] Steyer, T. E.; King, D. E.; Mainous, A. G., 3rd; Gilbert, G. Use of nutritional supplements for the prevention and treatment of hypercholesterolemia. Nutrition 2003, 19, 415-418.

[14] Rock, C. L. Multivitamin-multimineral supplements: who uses them? Am J Clin Nutr 2007, 85, 277S-279S, doi: 10.1093/ajen/85.1.277S.

[15] Bailey, R. L.; Gahche, J. J.; Miller, P. E.; Thomas, P. R.; Dwyer, J. T. Why US adults use dietary supplements. JAMA Intern Med 2013, 173, 355-361, doi: 10.1001/jamainternmed.2013.2299.

[16] Ervin, R. B.; Wright, J. D.; Kennedy-Stephenson, J. Use of dietary supplements in the United States, 1988-94. Vital Health Stat 11 1999, i-iii, 1-14. 
[17] Fairfield, K. M.; Fletcher, R. H. Vitamins for chronic disease prevention in adults: scientific review. JAMA 2002, 287, 31163126, doi: 10.1001/jama.287.23.3116.

[18] Blendon, R. J.; Benson, J. M.; Botta, M. D.; Weldon, K. J. Users' views of dietary supplements. JAMA Intern Med 2013, 173, 74-76, doi: 10.1001/2013.jamainternmed.311.

[19] Sesso, H. D.; Christen, W. G.; Bubes, V.; Smith, J. P.; MacFadyen, J.; Schvartz, M.; Manson, J. E.; Glynn, R. J.; Buring, J. E.; Gaziano, J. M. Multivitamins in the prevention of cardiovascular disease in men: the Physicians' Health Study II randomized controlled trial. JAMA 2012, 308, 1751-1760, doi: 10.1001/jama.2012.14805.

[20] Li, K.; Liu, C.; Kuang, X.; Deng, Q.; Zhao, F.; Li, D. Effects of Multivitamin and Multimineral Supplementation on Blood Pressure: A Meta-Analysis of 12 Randomized Controlled Trials. Nutrients 2018, 10, doi: 10.3390/nu10081018.

[21] Macpherson, H.; Pipingas, A.; Pase, M. P. Multivitaminmultimineral supplementation and mortality: a meta-analysis of randomized controlled trials. Am J Clin Nutr 2013, 97, 437444, doi: 10.3945/ajcn.112.049304.

[22] Soare, A.; Weiss, E. P.; Holloszy, J. O.; Fontana, L. Multiple dietary supplements do not affect metabolic and cardiovascular health. Aging (Albany NY) 2014, 6, 149-157, doi: 10.18632/aging. 100597 .

[23] Jenkins, D. J. A.; Spence, J. D.; Giovannucci, E. L.; Kim, Y. I.; Josse, R.; Vieth, R.; Blanco Mejia, S.; Viguiliouk, E.; Nishi, S.; Sahye-Pudaruth, S., et al. Supplemental Vitamins and Minerals for CVD Prevention and Treatment. J Am Coll Cardiol 2018, 71, 2570-2584, doi: 10.1016/j.jacc.2018.04.020.

[24] Huang, J.; Frohlich, J.; Ignaszewski, A. P. The impact of dietary changes and dietary supplements on lipid profile. Can J Cardiol 2011, 27, 488-505, doi: 10.1016/j.cjca.2010.12.077.

[25] Laditka, J. N.; Laditka, S. B.; Tait, E. M.; Tsulukidze, M. M. Use of dietary supplements for cognitive health: results of a national survey of adults in the United States. Am J Alzheimers Dis Other Demen 2012, 27, 55-64, doi: 10.1177/1533317511435662.

[26] Pillitteri, J. L.; Shiffman, S.; Rohay, J. M.; Harkins, A. M.; Burton, S. L.; Wadden, T. A. Use of dietary supplements for weight loss in the United States: results of a national survey. Obesity (Silver Spring) 2008, 16, 790-796, doi: 10.1038/oby.2007.136.

[27] Anders, S.; Schroeter, C. The impact of nutritional supplement intake on diet behavior and obesity outcomes. PLoS One 2017, 12, e0185258, doi: 10.1371/journal.pone.0185258.

[28] Angelo, G.; Drake, V. J.; Frei, B. Efficacy of Multivitamin/mineral Supplementation to Reduce Chronic Disease Risk: A Critical Review of the Evidence from Observational Studies and Randomized Controlled Trials. Crit Rev Food Sci Nutr 2015, 55, 1968-1991, doi: 10.1080/10408398.2014.912199.

[29] Biswas, S. K. Does the Interdependence between Oxidative Stress and Inflammation Explain the Antioxidant Paradox? Oxid Med Cell Longev 2016, 2016, 5698931, doi: 10.1155/2016/5698931.

[30] Steven, S.; Frenis, K.; Oelze, M.; Kalinovic, S.; Kuntic, M.; Bayo Jimenez, M. T.; Vujacic-Mirski, K.; Helmstadter, J.; Kroller-Schon, S.; Munzel, T., et al. Vascular Inflammation and Oxidative Stress: Major Triggers for Cardiovascular Disease. Oxid Med Cell Longev 2019, 2019, 7092151, doi:

\section{$10.1155 / 2019 / 7092151$}

[31] Fernandez-Garcia, J. C.; Cardona, F.; Tinahones, F. J. Inflammation, oxidative stress and metabolic syndrome: dietary modulation. Curr Vasc Pharmacol 2013, 11, 906-919, doi: $10.2174 / 15701611113116660175$.

[32] Li, C.; Miao, X.; Li, F.; Adhikari, B. K.; Liu, Y.; Sun, J.; Zhang, R.; Cai, L.; Liu, Q.; Wang, Y. Curcuminoids: Implication for inflammation and oxidative stress in cardiovascular diseases. Phytother Res 2019, 33, 1302-1317, doi: 10.1002/ptr.6324.

[33] Suen, J.; Thomas, J.; Kranz, A.; Vun, S.; Miller, M. Effect of Flavonoids on Oxidative Stress and Inflammation in Adults at Risk of Cardiovascular Disease: A Systematic Review. Healthcare (Basel) 2016, 4, doi: 10.3390/healthcare4030069.

[34] Fan, L.; Feng, Y.; Chen, G. C.; Qin, L. Q.; Fu, C. L.; Chen, L. $\mathrm{H}$. Effects of coenzyme Q10 supplementation on inflammatory markers: A systematic review and meta-analysis of randomized controlled trials. Pharmacol Res 2017, 119, 128-136, doi: 10.1016/j.phrs.2017.01.032.

[35] Moura, F. A.; de Andrade, K. Q.; dos Santos, J. C.; Goulart, M. O. Lipoic Acid: its antioxidant and anti-inflammatory role and clinical applications. Curr Top Med Chem 2015, 15, 458483, doi: 10.2174/1568026615666150114161358.

[36] Tabrizi, R.; Tamtaji, O. R.; Lankarani, K. B.; Mirhosseini, N.; Akbari, M.; Dadgostar, E.; Peymani, P.; Asemi, Z. The effects of resveratrol supplementation on biomarkers of inflammation and oxidative stress among patients with metabolic syndrome and related disorders: a systematic review and meta-analysis of randomized controlled trials. Food Funct 2018, 9, 61166128, doi: 10.1039/c8fo01259h.

[37] Patel, R. V.; Mistry, B. M.; Shinde, S. K.; Syed, R.; Singh, V.; Shin, H. S. Therapeutic potential of quercetin as a cardiovascular agent. Eur J Med Chem 2018, 155, 889-904, doi: 10.1016/j.ejmech.2018.06.053.

[38] Dickinson, A.; Blatman, J.; El-Dash, N.; Franco, J. C. Consumer usage and reasons for using dietary supplements: report of a series of surveys. J Am Coll Nutr 2014, 33, 176182, doi: 10.1080/07315724.2013.875423.

[39] Fennell, D. Determinants of supplement usage. Prev Med 2004, 39, 932-939, doi: 10.1016/j.ypmed.2004.03.031.

[40] Wallace, T. C.; McBurney, M.; Fulgoni, V. L., 3rd. Multivitamin/mineral supplement contribution to micronutrient intakes in the United States, 2007-2010. J Am Coll Nutr 2014, 33, 94-102, doi: $10.1080 / 07315724.2013 .846806$.

[41] Moore, J. X.; Chaudhary, N.; Akinyemiju, T. Metabolic Syndrome Prevalence by Race/Ethnicity and Sex in the United States, National Health and Nutrition Examination Survey, 1988-2012. Prev Chronic Dis 2017, 14, E24, doi: $10.5888 /$ pcd14.160287.

[42] American Heart Association. Lipid concentrations. Availabe online: http://www.americanheart.org/presenter.jhtml?identifier=183.

[43] National Center for Health Statistics. Analytic Guidelines, 2011-2014 and 2015-2016. Availabe online: https://wwwn.cdc.gov/nchs/data/nhanes/20112012/analyticguidelines/analytic guidelines 11 16.pdf (accessed on $14 \mathrm{Dec}$ ). 
[44] Afolayan, A. J.; Wintola, O. A. Dietary supplements in the management of hypertension and diabetes - a review. Afr $J$ Tradit Complement Altern Med 2014, 11, 248-258, doi: 10.4314/ajtcam.v11i3.35.

[45] Farias, J. G.; Molina, V. M.; Carrasco, R. A.; Zepeda, A. B.; Figueroa, E.; Letelier, P.; Castillo, R. L. Antioxidant Therapeutic Strategies for Cardiovascular Conditions Associated with Oxidative Stress. Nutrients 2017, 9, doi: 10.3390/nu9090966.

[46] Mozaffari, H.; Daneshzad, E.; Surkan, P. J.; Azadbakht, L. Dietary Total Antioxidant Capacity and Cardiovascular Disease Risk Factors: A Systematic Review of Observational Studies. J Am Coll Nutr 2018, 37, 533-545, doi: 10.1080/07315724.2018.1441079.

[47] Zemel, M. B. Nutritional and endocrine modulation of intracellular calcium: implications in obesity, insulin resistance and hypertension. Mol Cell Biochem 1998, 188, 129-136.

[48] Cornier, M. A.; Dabelea, D.; Hernandez, T. L.; Lindstrom, R. C.; Steig, A. J.; Stob, N. R.; Van Pelt, R. E.; Wang, H.; Eckel, R. H. The metabolic syndrome. Endocr Rev 2008, 29, 777822, doi: 10.1210/er.2008-0024

[49] Huskisson, E.; Maggini, S.; Ruf, M. The role of vitamins and minerals in energy metabolism and well-being. $J$ Int Med Res 2007, 35, 277-289, doi: 10.1177/147323000703500301.

[50] Cai, H.; Harrison, D. G. Endothelial dysfunction in cardiovascular diseases: the role of oxidant stress. Circ Res 2000, 87, 840-844, doi: 10.1161/01.res.87.10.840.

[51] Son, S. M. Role of vascular reactive oxygen species in development of vascular abnormalities in diabetes. Diabetes Res Clin Pract 2007, 77 Suppl 1, S65-70, doi: 10.1016/j.diabres.2007.01.036.

[52] Reaven, G. M. The insulin resistance syndrome: definition and dietary approaches to treatment. Annu Rev Nutr 2005, 25, 391406, doi: 10.1146/annurev.nutr.24.012003.132155.

[53] Barzegar-Amini, M.; Ghazizadeh, H.; Seyedi, S. M. R.; Sadeghnia, H. R.; Mohammadi, A.; Hassanzade-Daloee, M.; Barati, E.; Kharazmi-Khorassani, S.; Kharazmi-Khorassani, J.; Mohammadi-Bajgiran, M., et al. Serum vitamin E as a significant prognostic factor in patients with dyslipidemia disorders. Diabetes Metab Syndr 2019, 13, 666-671, doi: 10.1016/j.dsx.2018.11.034.

[54] Mirhosseini, N.; Rainsbury, J.; Kimball, S. M. Vitamin D Supplementation, Serum 25(OH)D Concentrations and Cardiovascular Disease Risk Factors: A Systematic Review and Meta-Analysis. Front Cardiovasc Med 2018, 5, 87, doi: 10.3389/fcvm.2018.00087.

[55] Lim, H. J.; Choi, Y. M.; Choue, R. Dietary intervention with emphasis on folate intake reduces serum lipids but not plasma homocysteine levels in hyperlipidemic patients. Nutr Res 2008, 28, 767-774, doi: 10.1016/j.nutres.2008.08.005.

[56] Vijayakumar, A.; Kim, E. K.; Kim, H.; Choi, Y. J.; Huh, K. B.; Chang, N. Effects of folic acid supplementation on serum homocysteine levels, lipid profiles, and vascular parameters in post-menopausal Korean women with type 2 diabetes mellitus. Nutr Res Pract 2017, 11, 327-333, doi: 10.4162/nrp.2017.11.4.327.

[57] Philpott, A. C.; Hubacek, J.; Sun, Y. C.; Hillard, D.; Anderson,
T. J. Niacin improves lipid profile but not endothelial function in patients with coronary artery disease on high dose statin therapy. Atherosclerosis 2013, 226, 453-458, doi: 10.1016/j.atherosclerosis.2012.10.067.

[58] Verma, H.; Garg, R. Effect of magnesium supplementation on type 2 diabetes associated cardiovascular risk factors: a systematic review and meta-analysis. J Hum Nutr Diet 2017, 30, 621-633, doi: 10.1111/jhn.12454.

[59] Jafarnejad, S.; Mahboobi, S.; McFarland, L. V.; Taghizadeh, M.; Rahimi, F. Meta-Analysis: Effects of Zinc Supplementation Alone or with Multi-Nutrients, on Glucose Control and Lipid Levels in Patients with Type 2 Diabetes. Prev Nutr Food Sci 2019, 24, 8-23, doi: 10.3746/pnf.2019.24.1.8.

[60] Suksomboon, N.; Poolsup, N.; Yuwanakorn, A. Systematic review and meta-analysis of the efficacy and safety of chromium supplementation in diabetes. $J$ Clin Pharm Ther 2014, 39, 292-306, doi: 10.1111/jcpt.12147.

[61] Albarracin, C.; Fuqua, B.; Geohas, J.; Juturu, V.; Finch, M. R.; Komorowski, J. R. Combination of chromium and biotin improves coronary risk factors in hypercholesterolemic type 2 diabetes mellitus: a placebo-controlled, double-blind randomized clinical trial. J Cardiometab Syndr 2007, 2, 91-97.

[62] Wolide, A. D.; Zawdie, B.; Alemayehu, T.; Tadesse, S. Association of trace metal elements with lipid profiles in type 2 diabetes mellitus patients: a cross sectional study. $B M C$ Endocr Disord 2017, 17, 64, doi: 10.1186/s12902-017-0217-z.

[63] Mao, S.; Zhang, A.; Huang, S. Selenium supplementation and the risk of type 2 diabetes mellitus: a meta-analysis of randomized controlled trials. Endocrine 2014, 47, 758-763, doi: 10.1007/s12020-014-0298-7.

[64] Jorat, M. V.; Tabrizi, R.; Mirhosseini, N.; Lankarani, K. B.; Akbari, M.; Heydari, S. T.; Mottaghi, R.; Asemi, Z. The effects of coenzyme Q10 supplementation on lipid profiles among patients with coronary artery disease: a systematic review and meta-analysis of randomized controlled trials. Lipids Health Dis 2018, 17, 230, doi: 10.1186/s12944-018-0876-4.

[65] Appel, L. J.; Brands, M. W.; Daniels, S. R.; Karanja, N.; Elmer, P. J.; Sacks, F. M.; American Heart, A. Dietary approaches to prevent and treat hypertension: a scientific statement from the American Heart Association. Hypertension 2006, 47, 296-308, doi: 10.1161/01.HYP.0000202568.01167.B6.

[66] Forman, J. P.; Rimm, E. B.; Stampfer, M. J.; Curhan, G. C. Folate intake and the risk of incident hypertension among US women. JAMA 2005, 293, 320-329, doi: 10.1001/jama.293.3.320.

[67] Ness, A. R.; Chee, D.; Elliott, P. Vitamin C and blood pressure--an overview. J Hum Hypertens 1997, 11, 343-350.

[68] Borghi, C.; Cicero, A. F. Nutraceuticals with a clinically detectable blood pressure-lowering effect: a review of available randomized clinical trials and their meta-analyses. $\mathrm{Br} J$ Clin Pharmacol 2017, 83, 163-171, doi: 10.1111/bcp.12902.

[69] Emami, M. R.; Safabakhsh, M.; Alizadeh, S.; Asbaghi, O.; Khosroshahi, M. Z. Effect of vitamin E supplementation on blood pressure: a systematic review and meta-analysis. J Hum Hypertens 2019, 33, 499-507, doi: 10.1038/s41371-019-01920 . 
[70] Aybak, M.; Sermet, A.; Ayyildiz, M. O.; Karakilcik, A. Z. Effect of oral pyridoxine hydrochloride supplementation on arterial blood pressure in patients with essential hypertension. Arzneimittelforschung 1995, 45, 1271-1273.

[71] McRae, M. P. High-dose folic acid supplementation effects on endothelial function and blood pressure in hypertensive patients: a meta-analysis of randomized controlled clinical trials. $J$ Chiropr Med 2009, 8, 15-24, doi: 10.1016/j.jcm.2008.09.001.

[72] Mangoni, A. A.; Sherwood, R. A.; Swift, C. G.; Jackson, S. H. Folic acid enhances endothelial function and reduces blood pressure in smokers: a randomized controlled trial. $J$ Intern Med 2002, 252, 497-503.

[73] Bays, H. E.; Rader, D. J. Does nicotinic acid (niacin) lower blood pressure? Int J Clin Pract 2009, 63, 151-159, doi: 10.1111/j.1742-1241.2008.01934.x.

[74] Alaei-Shahmiri, F.; Soares, M. J.; Zhao, Y.; Sherriff, J. The impact of thiamine supplementation on blood pressure, serum lipids and C-reactive protein in individuals with hyperglycemia: a randomised, double-blind cross-over trial. Diabetes Metab Syndr 2015, 9, 213-217, doi: 10.1016/j.dsx.2015.04.014.

[75] Horigan, G.; McNulty, H.; Ward, M.; Strain, J. J.; Purvis, J.; Scott, J. M. Riboflavin lowers blood pressure in cardiovascular disease patients homozygous for the $677 \mathrm{C}-->\mathrm{T}$ polymorphism in MTHFR. J Hypertens 2010, 28, 478-486, doi: 10.1097/HJH.0b013e328334c126.

[76] Stranges, S.; Guallar, E. Dietary iron and blood pressure. BMJ 2008, 337, a547, doi: 10.1136/bmj.a547.

[77] Cappuccio, F. P.; Elliott, P.; Allender, P. S.; Pryer, J.; Follman, D. A.; Cutler, J. A. Epidemiologic association between dietary calcium intake and blood pressure: a meta-analysis of published data. Am J Epidemiol 1995, 142, 935-945, doi: 10.1093/oxfordjournals.aje.a117741.

[78] Rosenfeldt, F. L.; Haas, S. J.; Krum, H.; Hadj, A.; Ng, K.; Leong, J. Y.; Watts, G. F. Coenzyme Q10 in the treatment of hypertension: a meta-analysis of the clinical trials. J Hum Hypertens 2007, 21, 297-306, doi: 10.1038/sj.jhh.1002138.

[79] Zhao, J. V.; Schooling, C. M.; Zhao, J. X. The effects of folate supplementation on glucose metabolism and risk of type 2 diabetes: a systematic review and meta-analysis of randomized controlled trials. Ann Epidemiol 2018, 28, 249257 e241, doi: 10.1016/j.annepidem.2018.02.001.

[80] Balbi, M. E.; Tonin, F. S.; Mendes, A. M.; Borba, H. H.; Wiens, A.; Fernandez-Llimos, F.; Pontarolo, R. Antioxidant effects of vitamins in type 2 diabetes: a meta-analysis of randomized controlled trials. Diabetol Metab Syndr 2018, 10, 18, doi: 10.1186/s13098-018-0318-5.

[81] Ashor, A. W.; Werner, A. D.; Lara, J.; Willis, N. D.; Mathers, J. C.; Siervo, M. Effects of vitamin C supplementation on glycaemic control: a systematic review and meta-analysis of randomised controlled trials. Eur J Clin Nutr 2017, 71, 13711380, doi: 10.1038/ejen.2017.24.

[82] Kim, H. H.; Kang, Y. R.; Choi, H. Y.; Lee, J. Y.; Oh, J. B.; Kim, J. S.; Kim, Y. C.; Lee, K. W.; Kwon, Y. I. Postprandial anti-hyperglycemic effect of vitamin B6 (pyridoxine) administration in healthy individuals. Food Sci Biotechnol 2019, 28, 907-911, doi: 10.1007/s10068-018-0534-7.

[83] Moen, G. H.; Qvigstad, E.; Birkeland, K. I.; Evans, D. M.; Sommer, C. Are serum concentrations of vitamin B-12 causally related to cardiometabolic risk factors and disease? A Mendelian randomization study. Am J Clin Nutr 2018, 108, 398-404, doi: 10.1093/ajen/nqy101.

[84] Polo, V.; Saibene, A.; Pontiroli, A. E. Nicotinamide improves insulin secretion and metabolic control in lean type 2 diabetic patients with secondary failure to sulphonylureas. Acta Diabetol 1998, 35, 61-64.

[85] Karkabounas, S.; Papadopoulos, N.; Anastasiadou, C.; Gubili, C.; Peschos, D.; Daskalou, T.; Fikioris, N.; Simos, Y. V.; Kontargiris, E.; Gianakopoulos, X., et al. Effects of alphaLipoic Acid, Carnosine, and Thiamine Supplementation in Obese Patients with Type 2 Diabetes Mellitus: A Randomized, Double-Blind Study. J Med Food 2018, 21, 1197-1203, doi: 10.1089/jmf.2018.0007.

[86] Wang, X.; Wu, W.; Zheng, W.; Fang, X.; Chen, L.; Rink, L.; Min, J.; Wang, F. Zinc supplementation improves glycemic control for diabetes prevention and management: a systematic review and meta-analysis of randomized controlled trials. $\mathrm{Am}$ $J \quad$ Clin Nutr 2019, 10.1093/ajen/nqz041, doi: 10.1093/ajen/nqz041.

[87] Sitasawad, S.; Deshpande, M.; Katdare, M.; Tirth, S.; Parab, P. Beneficial effect of supplementation with copper sulfate on STZ-diabetic mice (IDDM). Diabetes Res Clin Pract 2001, $52,77-84$

[88] Johnson, M. A.; Smith, M. M.; Edmonds, J. T. Copper, iron, zinc, and manganese in dietary supplements, infant formulas, and ready-to-eat breakfast cereals. Am J Clin Nutr 1998, 67, 1035S-1040S, doi: 10.1093/ajen/67.5.1035S.

[89] Lee, D. H.; Gross, M. D.; Jacobs, D. R., Jr.; Cardiovascular Risk Development in Young Adults, S. Association of serum carotenoids and tocopherols with gamma-glutamyltransferase: the Cardiovascular Risk Development in Young Adults (CARDIA) Study. Clin Chem 2004, 50, 582-588, doi: 10.1373/clinchem.2003.028852.

[90] Lee, D. H.; Jacobs, D. R., Jr.; Gross, M.; Kiefe, C. I.; Roseman, J.; Lewis, C. E.; Steffes, M. Gammaglutamyltransferase is a predictor of incident diabetes and hypertension: the Coronary Artery Risk Development in Young Adults (CARDIA) Study. Clin Chem 2003, 49, 13581366, doi: 10.1373/49.8.1358.

[91] Bhardwaj, P.; Khanna, D. Green tea catechins: defensive role in cardiovascular disorders. Chin J Nat Med 2013, 11, 345353, doi: 10.1016/S1875-5364(13)60051-5. 